\title{
Enunciação e sentidos: implicações para a revisão de textos
}

\author{
Rivânia Maria Trotta Sant'Ana*
}

\begin{abstract}
Resumo
Entendemos a revisão de textos como uma prática que se constitui, basicamente, de uma atividade de interpretação. Como tal, a revisão de textos demanda atenção aos sentidos, que se movem à medida que fazemos intervenções no texto original. Toda alteração implica uma mudança, mesmo que sutil, de sentidos. Curiosamente, não é muito comum encontrar reflexões acerca das implicações semânticas da prática de revisão de textos. Tomando a interpretação como constitutiva da prática de revisão, pretendo refletir, numa perspectiva enunciativa, sobre aspectos enunciativos resultantes de intervenções realizadas em um texto. Para isso, assumimos como perspectiva teórica a Semântica da Enunciação, desenvolvida por Eduardo Guimarães, e utilizamos alguns conceitos da Análise do Discurso de orientação pecheutiana. Tomamos como corpus para análise intervenções de um revisor/editor em um artigo de nossa autoria.
\end{abstract}

Palavras-chave: Enunciação. Acontecimento. Sentidos. Revisão de textos.

\section{Enunciation and meanings: implications for text revisions}

\begin{abstract}
I understand the text revision as a practice that consists itself, basically, from an interpretation activity. As such, it requires attention to the meanings, which changes in a movement, according to the interventions in the original text. Every single alteration implicates in a change, even if subtle, of the meanings. Interestingly, it is not very common to find reflections about the semantic implications in the practice of text revision. Considering interpretation as a constitutive part of the revision practice, I intend to build a reflection, from an enunciative perspective, about enunciative aspects resulted from interventions in a text. For that, I assume as theoretical perspective the Semantics of Enunciation, developed by Eduardo Guimarães, and some concepts from the Discourse Analysis in pecheutian orientation. I take as corpus for this analysis interventions from a reviewer/editor in an article of my own authorship.
\end{abstract}

Keywords: Enunciation. Event. Meanings. Text revision.

Recebido: 31/01/2019

Aceito: $24 / 04 / 2019$

*Universidade Federal de Ouro Preto (UFOP). Professora Associada do Departamento de Letras. 
Em artigo anterior sobre a revisão e a tradução de textos e parâmetros para a formação de revisores e tradutores (SANT'ANA; GONÇALVES, 2010, p. 227), tomando como base a afirmação de Nestrovski (1996) de que toda edição é uma interpretação, estabelecemos um paralelo, identificando a atividade de revisar um texto ao gesto de ler, interpretar. ${ }^{1} \mathrm{O}$ revisor seria, basicamente, um leitor; privilegiado, uma vez que pode fazer intervenções no texto lido. Essa prerrogativa do leitor/revisor marca a especificidade da leitura/revisão. No referido artigo, afirmávamos que o revisor, no ato da leitura que constitui a atividade de revisão, está sujeito à projeção de pontos de vista decorrentes de suas filiações, do lugar adotado, conscientemente ou não, para a interpretação. Estava implícita, no que afirmávamos, a concepção de que é a interpretação realizada pelo revisor que determina parte das escolhas que ele faz durante a revisão.

Assim, além de considerarmos os aspectos normativos ligados a questões gramaticais, ortográficas e editoriais, que costumam ser destacados quando o tema é a revisão de textos, apontávamos, naquele momento, ainda que de forma incipiente, para a necessidade de estarmos atentos aos sentidos durante o exercício da atividade de revisão. Embora essa afirmação pareça óbvia, e talvez o seja mesmo, as discussões que comumente se fazem sobre a tarefa da revisão não costumam se aprofundar nos aspectos semânticos dos textos revisados nem nos efeitos semânticos das intervenções realizadas pelos revisores.

A concepção que se tem sobre os aspectos semânticos envolvidos na tarefa do revisor se revela superficial em enunciados correntes no âmbito do ensino e da prática da revisão de textos, tais como: “Ao propor uma alteração no texto, é preciso tomar cuidado para não mudar o sentido original.", "É preciso manter o sentido original." No geral, não se questionam esses enunciados. É como se eles fossem absolutamente claros para todos. Gostaríamos de questioná-los. Esclarecemos: questioná-los, mas não refutá-los, pois não se trata de pensar que não haja no texto sentido algum para sustentar determinada leitura. Como bem explicam Jamal e Dalmachio (2011, p. 9), o sentido deveria ser percebido "não como algo previsto e determinado, conforme assumido por uma posição referencialista da linguagem, mas como algo que pode deslizar nas possibilidades asseguradas enunciativamente pela historicidade que o sustenta". Assim, embora, da nossa perspectiva, o sentido não seja compreendido como determinado, fechado ou até mesmo fixo no texto, ele e seu movimento são assegurados pela historicidade da língua e dos enunciados. Dessa forma, questionar os enunciados referidos significa apurar o olhar sobre eles, para compreendê-los melhor. Por exemplo, deveríamos nos perguntar: $\mathrm{O}$ que é o sentido original do texto? Considerando o processo da escrita pelo autor e o da leitura pelo revisor, é possível falar em "o sentido", no singular? É possível realizar uma intervenção no texto sem provocar deslocamento de sentidos, isto é, sem provocar mudanças de sentido, mesmo que sutis? Essas são algumas das perguntas relevantes numa perspectiva enunciativa da linguagem, à qual nos filiamos.

Tendo em vista a relevância da reflexão sobre os sentidos, nossa proposta, no presente artigo, é retomar o tema da revisão como interpretação, apenas insinuado na reflexão elaborada, em parceria com Gonçalves, em 2010, para desenvolvê-lo, embora sem esgotá-lo, na tentativa de compreender melhor o papel dos sentidos na atividade de revisão e suas decorrências para a própria prática do revisor e para a interlocução que se pode/deve estabelecer entre esses e os autores.

Para o desenvolvimento deste trabalho, tomamos como referencial pressupostos teóricos da Semântica do Acontecimento, desenvolvida por Eduardo Guimarães, e da Análise do Discurso, de filiação pecheutiana, desenvolvida por Eni Orlandi.

Primeiramente, discorreremos sobre alguns conceitos-chave para esta reflexão, tais como: enunciação, acontecimento enunciativo, (GUIMARÃES, 1995; 2005); texto, interpretação e real

1 A expressão 'gesto de', de Pêcheux (1969, apud ORLANDI, 2003, p. 22), significa “um ato a nível simbólico”, afastandose do conceito de "ato" da Pragmática, que se baseia numa intencionalidade consciente. É este o sentido da palavra 'gesto' que utilizamos neste artigo quando dizemos 'gestos de leitura' ou 'gestos de interpretação'. 
do sentido (ORLANDI, 1996; 2003; 2007; 2008). Após os esclarecimentos acerca dos conceitos e pressupostos teóricos nos quais ancoramos nossa reflexão, passamos à análise das intervenções de um editor/revisor em texto de nossa autoria. Constituem o corpus da reflexão aqui desenvolvida algumas passagens de nosso texto sobre as quais estabelecemos com o editor/revisor um diálogo acerca do movimento dos sentidos resultante de sua intervenção, tanto para acatá-la quanto para refutá-la.

Esclarecemos que nosso objetivo não é pôr em questão a revisão realizada pelo profissional, que, queremos ressaltar, fez um trabalho minucioso, competente e com quem estabelecemos um diálogo profícuo que resultou em muitas melhorias no nosso texto. Acatamos todas as correções relativas a aspectos gramaticais e editoriais que ele fez e também parte das sugestões resultantes da sua interpretação. Ele, por sua vez, esteve atento a todas as nossas considerações e explicações para o fato de não aceitarmos algumas de suas propostas de alteração e respeitou as nossas decisões. Esclarecemos também que o consultamos, antes de escrever este artigo, sobre a possibilidade de utilizar suas intervenções como corpus para a análise aqui desenvolvida. Finalmente, esclarecemos que, embora ele tenha nos concedido sua autorização, preservaremos sua identidade. Por isso, e porque o corpus utilizado é constituído por trechos do texto ainda em processo de revisão, anterior à publicação da versão final do artigo, não será informada a referência bibliográfica dos excertos citados.

\section{Escrita e revisão: processos de significação}

Na perspectiva aqui adotada, a escrita é compreendida como um modo de enunciação, como processo, portanto. A enunciação é apreendida como um "acontecimento de linguagem perpassado pelo interdiscurso" (GUIMARÃES, 1995, p. 65), isto é, um acontecimento de linguagem perpassado por uma memória de sentidos que afeta a língua. Isso significa que, nessa perspectiva, a enunciação não é simplesmente o ato de dizer algo numa situação específica, mas inclui a historicidade da língua e dos sentidos. Para Guimarães (2005), toda enunciação é constituída por um presente, um passado e a projeção de um futuro de dizeres. Essa temporalidade complexa que constitui a enunciação, ou acontecimento de linguagem, produz sentidos opacos, não evidentes, porque marcados por uma "alteridade", isto é, por uma densidade histórica, resultante da materialidade da língua e do discurso, que provoca resistência para a escrita, a leitura e, entendemos que, consequentemente, para a revisão. Quando dizemos ou ouvimos que o sentido de um texto é claro, evidente, e o texto é, portanto, legível, é sempre pertinente perguntar para quem, quando e em que circunstâncias o sentido é evidente. Concebemos, com Orlandi (1996, p. 9), que a legibilidade de um texto é "uma questão de 'graus' e não de tudo ou nada. Uma questão de condições e não de essência”. Da nossa perspectiva, as condições de produção dos sentidos é relevante porque entendemos que eles são constituídos na enunciação, no acontecimento de linguagem, pela confluência de uma memória e um presente, que criam possibilidades para uma futuridade de dizeres. Os sentidos são, portanto, uma questão enunciativa, algo de natureza "relacional, que, ao surgir, é capaz de originar alteração no já posto, no já estabelecido" (JAMAL; DALMACHIO, 2011, p. 8).

Quanto ao texto, ele é, neste trabalho, compreendido como resultado de um processo de formulação pelo qual o sujeito constrói a textualidade, dando contorno material ao seu dizer e construindo uma orientação discursiva que lineariza o discurso, criando, para o texto, um efeito de unidade, completude, fechamento (ORLANDI, 2008). Para Orlandi, a orientação discursiva ocorre à medida que, ao longo da formulação, alguns sentidos são postos em evidência enquanto outros são apagados.

Diz-se 'efeito de unidade, completude, fechamento' porque, à semelhança do discurso, que se caracteriza por heterogeneidade, multiplicidade e fragmentação, todo texto é múltiplo e incompleto, 
uma vez que: há nele lacunas, pois não é possível abordar todos os aspectos de um tema; os apagamentos que produz também significam pela ausência; os pontos de contato entre o presente, o passado e o futuro que constituem o acontecimento do dizer são pontos de encontro e de dispersão, que permitem deslocamentos de sentido; no texto, "podemos encontrar enunciados de discursos diversos, que derivam de várias formações discursivas" (ORLANDI, 1996, p. 53), das quais, muitas vezes, nem o próprio autor tem consciência. Logo, no texto, os sentidos não estão engessados, eles são passíveis de movimento. É por isso que enunciados como "Ao propor uma alteração no texto, é preciso tomar cuidado para não mudar o sentido original." e "É preciso manter o sentido original.", mencionados na introdução deste artigo, precisam ser questionados. É por isso também que usar a palavra 'sentidos', no plural, talvez seja mais apropriado se considerarmos o texto como resultado de um processo complexo que inclui a escrita, a leitura e a revisão.

Porém, afirmar que os sentidos são passíveis de movimento, "que o sentido sempre pode ser outro" (ORLANDI, 2003, p. 21), não significa considerar que o sentido pode ser um sentido qualquer. Como explica Orlandi (2003, p. 22), há determinações históricas para o sentido. Assim, a interpretação, que "está presente em toda e qualquer manifestação de linguagem" (ORLANDI, 2007, p. 9), ocorre em toda leitura, em toda atividade de revisão, e pode ser também compreendida como formulação, trabalho que se faz sobre a linguagem historicamente materializada num texto. Um trabalho que, pela dispersão dos sentidos, pode produzir deslocamentos, captar outros sentidos possíveis, não vislumbrados pelo próprio autor, e até mesmo resultar em equívocos.

No que concerne à prática de revisão de textos, além do fato de ela se dar pela interpretação, como qualquer outro gesto de leitura, é ainda necessário considerar sua especificidade, que é o fato de ela se realizar pelas intervenções que o revisor realiza no texto de outro.

No livro A leitura e os leitores, Orlandi afirma que "[...] um gesto de interpretação é uma intervenção no real do sentido. Daí o peso e a importância de interpretar." (ORLANDI, 2003, p. 22). Por que a interpretação é uma intervenção no real dos sentidos? Porque toda interpretação se dá num espaço de confluência entre o previsível, que a historicidade dos dizeres delineia, e as possibilidades postas pela relação entre a memória e o presente do dizer. Ora, se toda interpretação é uma intervenção no real dos sentidos, consequentemente, podemos dizer que a prática da revisão de textos, que opera uma interpretação e que, além disso, produz modificações na materialidade do texto objeto da interpretação, é também, e mais radicalmente, uma intervenção no real dos sentidos. Precisamos, então, compreender como a expressão 'o real' se constituiu historicamente no quadro dos estudos da linguagem, em especial, no domínio da Análise do Discurso.

O conceito de Real se origina no campo da Psicanálise. Segundo Chaves (2009), nos escritos de Lacan, o conceito de Real aparece associado aos conceitos de Imaginário e Simbólico, mas a forma de conceber esses conceitos sofre mudanças no decorrer da reflexão elaborada por Lacan em seus escritos. De forma bem resumida, podemos dizer que o Imaginário diz respeito à relação que o sujeito estabelece com a formação da sua imagem e do seu "Eu" (desenvolvimento da consciência do corpo próprio), o Simbólico remete à linguagem, e o Real, compreendido como distinto da realidade, seria um efeito do Simbólico (VANIER, 2005, apud CHAVES, 2009), isto é, só se chegaria ao Real pelo Simbólico. O Real é compreendido como da ordem do impossível, uma vez que não se pode apreendê-lo na sua totalidade. A apreensão do Real se daria pela sua ocorrência como falta:

A referência ao Real impõe a diferenciação de dois planos intrinsecamente relacionados: o da impossibilidade - o Real é o impossível - e o da ocorrência - o Real como aquilo que não cessa de não se escrever, retornando sempre ao mesmo lugar. Justo por impossível, não cessa de comparecer como falta. (LEITE, 1993, p. 89).

No campo da Análise do Discurso, encontramos também o conceito de Real em expressões como 'o real da língua', 'o real do sentido'. Baseado no conceito lacaniano, o conceito de Real ganha 
especificidade nos estudos da linguagem e do discurso, embora mantenha alguns de seus traços originais de sentido. Segundo Ferreira (1999), Milner, em texto de 1989, considera como pressuposto que, "em matéria de língua, tudo não se pode dizer". Assim, o real da língua também seria da ordem do impossível, uma vez que ela não pode ser apreendida em sua totalidade. Da mesma forma, na Análise do Discurso de filiação pêcheutiana, quando se fala em real da língua ou em real do sentido, o que está em jogo é o que excede, o que escapa, mas sempre retorna, emerge. O real do sentido, portanto, também seria da ordem do impossível, uma vez que sua apreensão nunca é completa.

Embora os sentidos sejam históricos, e, portanto, possam ser recuperáveis por uma memória de dizeres, essa memória não é acessível a todos. Quando o é, apenas parte dessa memória é acessível aos sujeitos. Conforme Orlandi (2007, p. 63), “A ordem simbólica, configurada pelo real da língua e pelo real da história, faz com que tudo não possa ser dito e, por outro lado, haja em todo dizer uma parte inacessível ao próprio sujeito.", o que implica que as nossas palavras dizem até aquilo que desconhecemos. Isso se dá porque as palavras têm uma historicidade e, portanto, significam, no nosso dizer, também dizeres anteriores.

Os aspectos da incompletude e do movimento dos sentidos têm decorrências para os gestos de interpretação que são realizados pelo revisor durante seu trabalho e que determinam muitas das intervenções que ele faz. Ele pode fazer uma alteração que implica um deslocamento de sentidos que não se sustenta na materialidade do texto, por não ter acesso a muitos dos sentidos que essa materialidade evoca. Como pode também captar um sentido sustentado na materialidade histórica do texto, mas que não era acessível ao próprio autor. Diante disso, algumas questões se fazem necessárias: Como lidar com a impossibilidade do real da língua e a incompletude dos sentidos durante a atividade de revisão de textos? É possível ensinar a lidar com essa impossibilidade? No que diz respeito à significação do texto, o que seria uma revisão adequada?

Passamos à análise do corpus, para, então, voltarmos a essas questões.

\section{Análise das intervenções}

Para esta análise, apresentamos o excerto original, em seguida, o excerto com as alterações propostas pelo revisor e, finalmente, a reflexão acerca das alterações e seus efeitos de sentido. As passagens do texto original e as intervenções nelas realizadas se apresentam grifadas. Não serão discutidas neste artigo as alterações de natureza editorial.

É preciso ainda informar que o texto revisado aborda um movimento literário modernista de uma cidade do interior mineiro, ocorrido na década de 20 do séc. XX.

\section{Excerto 1}

Original:

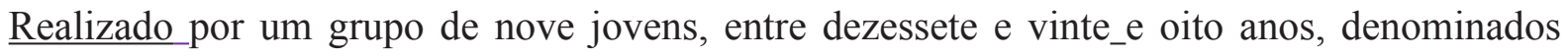
por Mário e Oswald de Andrade de Ases de Cataguases, o movimento produziu uma revista, denominada Verde - Revista de Arte e Cultura, cujo nome acabou por se aplicar ao próprio movimento, e uma editora, também denominada Verde. Verde Editora. Quanto ao nome Verde, que levou o movimento de Cataguases a ser, algumas vezes, identificado, equivocadamente, com o movimento Verde-Amarelo, foi escolhido para fazer alusão à juventude do grupo e motivado pelo livro de Augusto Meyer, Coração Verde, de 1926. 
Revisado:

Protagonizado por um grupo de nove jovens, entre 17 e 28 anos, denominados por Mário e Oswald de Andrade "Ases de Cataguases", o movimento produziu a revista Verde - Revista de Arte e Cultura, cujo nome acabou por se aplicar ao próprio movimento, e uma editora, também intitulada Verde. O nome Verde, que levou o movimento de Cataguases a ser, algumas vezes, identificado, equivocadamente, com o movimento Verde-Amarelo, foi escolhido tanto para fazer alusão à juventude do grupo quanto para referir-se ao livro de Augusto Meyer, Coração Verde, de 1926.

Nessa passagem do texto, o revisor fez várias alterações, entre as quais se encontram aquelas necessárias para atender às normas de edição da revista, tais como o acréscimo das aspas na expressão “Ases de Cataguases” e a utilização dos símbolos matemáticos para representar números, em vez do registro por extenso utilizado na primeira versão. Há outras alterações que foram motivadas pela busca de um texto mais objetivo, sem as repetições presentes no original. Todas essas alterações foram aceitas sem questionamento e não cabe discuti-las aqui. O que nos interessa discutir são as alterações grifadas, uma vez que elas implicam uma mudança de sentido mais radical.

Na primeira linha do excerto do texto original, temos a palavra 'realizado', utilizada para informar o leitor sobre as pessoas que iniciaram e conduziram o movimento modernista em questão. O revisor trocou a palavra 'realizado' por 'protagonizado'. A princípio, podemos dizer que não havia necessidade dessa alteração, uma vez que a palavra utilizada no original não fere nenhuma norma gramatical ou editorial, também não apresenta problemas para a compreensão do leitor, pois 'realizado' é uma palavra corrente no português do Brasil. Essa afirmação é válida especialmente se considerarmos os leitores especializados que têm acesso à revista em que o artigo foi publicado. A motivação para a alteração proposta parece ter sido um preferência do revisor. E essa alteração provocou uma mudança de sentido. A palavra 'protagonizado' evoca o sentido histórico de desempenhar uma ação de forma ativa, ocupando um lugar de destaque no desenrolar dos acontecimentos. A escolha do revisor, embora não necessária, traz para o texto esse sentido que descreve, com mais precisão, o papel desempenhado pelos escritores que, de fato, "protagonizaram" o movimento, destacando-se no País e no exterior. Nesse sentido, no acontecimento da revisão, o revisor captou, pela sua interpretação do texto, um sentido possível e relevante para nosso artigo. Um sentido ao qual não tivemos acesso no acontecimento enunciativo da escrita, da elaboração do texto. Essa alteração foi incorporada à versão final.

Ainda nesse excerto, temos as alterações da palavra 'denominada' por 'intitulada' e da expressão 'motivada pelo livro' por 'para referir-se ao livro'. Nos dois casos, a intervenção do revisor resulta em problemas para a significação do texto. No primeiro caso, entendemos que é mais apropriado, porque historicamente mais recorrente, utilizar a palavra 'denominar', como consta no original, do que 'intitular', para nos referirmos ao ato de dar nome a uma instituição, no caso, uma editora.

A última intervenção desse trecho provocou uma mudança de sentido que não estava no campo das possibilidades desse dizer. Os escritores aos quais nos referíamos no texto, conforme um deles explica em entrevista, utilizaram o nome Verde, para nomear o movimento, motivados pelo livro de Augusto Meyer, Coração Verde. Afirmar que eles escolheram esse nome para fazerem referência ao livro muda o sentido, acrescentando a intencionalidade explícita de pôr o livro em evidência, de informar os leitores sobre ele, o que não acontece, uma vez que a referência explícita ao livro de Meyer só aparece na referida entrevista. Assim, não poderíamos sustentar esse dizer, tendo em vista as informações que tínhamos. 


\section{Excerto 2}

Original:

As condições sociais precárias aparecem também tematizadas nos poemas Maria Lavadeira e Pedreira, de Francisco Inácio Peixoto. Em Maria Lavadeira, temos a situação difícil da lavadeira não apenas por sua condição social, mas também por sua condição de mulher que dá suporte a toda a família.

\section{Revisado:}

As condições sociais precárias aparecem também tematizadas nos poemas Maria Lavadeira e Pedreira, de Francisco Inácio Peixoto. Em Maria Lavadeira, temos a situação opressiva da lavadeira não apenas por sua condição social, mas também por sua condição de mulher que dá suporte a toda a família.

No excerto 2, temos uma intervenção que opera um deslocamento de sentido que é uma possibilidade sustentada pela configuração material do texto original. A palavra 'difícil', utilizada nesse excerto, tem uma história de usos ligada a situações, pessoas, objetos, tarefas que impõem uma resistência, que demandam esforço, ou que se caracterizam como algo trabalhoso, desagradável, penoso, complicado ou inacessível, entre outros usos em que a palavra assume traços de sentido que se aproximam e se distanciam. ${ }^{2}$ Essa palavra foi substituída, pelo revisor, pela palavra 'opressiva'. Outra vez, podemos dizer que não havia necessidade dessa intervenção, que ela se baseia numa preferência do revisor. Mas a troca provoca uma melhoria no texto, porque a palavra 'opressiva', mantendo traços de sentido da palavra 'difícil', imprime maior força argumentativa ao texto, ao trazer especificidade para a dificuldade discutida naquele acontecimento de linguagem. A alteração feita pelo revisor neste ponto do texto recupera enunciados históricos utilizados para denúncia social, nos quais palavras como 'opressiva', 'opressão' e 'oprimir' são recorrentes. Na relação com o poema discutido no trecho destacado, essas palavras e os discursos que elas evocam ganham pertinência, fazendo significar a voz do poeta, que, em consonância com outras vozes, integrava o movimento modernista já do final da década de vinte, em que se antecipavam as denúncias sociais que seriam recorrentes no modernismo dos anos trinta. Aqui, mais uma vez, o revisor capta um sentido que nos passou despercebido no acontecimento da escrita.

\section{Excerto 3}

\section{Original:}

Pela ferrovia chegaram também muitos imigrantes, nacionais e estrangeiros, com suas ideias e $\underline{\text { suas }}$ culturas diferentes.

Revisado:

Pela ferrovia chegaram também muitos imigrantes, nacionais e estrangeiros, portadores de ideias e culturas diversas.

No excerto 3, temos alterações que parecem ter sido motivadas por uma suposta necessidade de eliminar a repetição do pronome 'suas'. Acredito que esta tenha sido a motivação, pois eliminar repetições é uma prática comum no trabalho dos revisores. Já para a troca da palavra 'diferentes'

2 Ver Dicionário Houaiss da Língua Portuguesa (HOUAISS, 2007). 
pela palavra 'diversas' não encontro uma justificativa a não ser uma preferência pessoal. Neste exemplo, porém, as intervenções não foram felizes. Em primeiro lugar, dizer que os estrangeiros são "portadores" de ideias e culturas diversas não parece ser adequado. Nos dicionários, o significado de portar é carregar, manter, levar algo consigo. ${ }^{3}$ Não me parece ser adequado dizer 'portar culturas'. ${ }^{4}$ Os deslocamentos de sentido resultantes da intervenção pelo revisor nesse trecho não são meramente estilísticos como podem parecer, eles têm implicações mais profundas para os efeitos de sentido. Por exemplo, a forma "ideias e culturas diferentes" põe em evidência os aspectos envolvidos no sentido da "diferença", que contemplam a interlocução, os conflitos e as trocas decorrentes do encontro de pessoas e culturas diferentes. Pensamos que a palavra 'diversas' enfraquece esses efeitos de sentido e reforça o aspecto da multiplicidade, da quantidade. Neste caso, não concordamos com a alteração proposta e, embora não consideremos defeito toda repetição de palavras ou expressões, propusemos uma alternativa em que a repetição do pronome possessivo fosse eliminada. Entramos num acordo, e o resultado foi: "Pela ferrovia, chegaram também muitos imigrantes, nacionais e estrangeiros, com suas ideias e culturas diferentes".

\section{Excerto 4}

\section{Original:}

Ao termos acesso à produção literária, crítica e teórica dos modernistas de Cataguases, tanto aquela publicada na revista Verde quanto a que eles publicaram nos livros da Verde Editora e em outros jornais e revistas da época, verificamos que, ao lado daqueles textos que são meros exercícios de escrita, sem valor estético, encontramos outros bem elaborados, que apresentam, de fato, renovação linguística e temática e que revelam terem aqueles jovens levado a literatura a sério.

\section{Revisado:}

Ao termos acesso à produção literária, crítica e teórica dos modernistas de Cataguases, tanto aquela publicada na revista Verde quanto a que eles publicaram nos livros da Verde Editora e em outros jornais e revistas da época, verificamos que, ao lado daqueles textos que são meros exercícios de escrita, sem valor estético, encontramos outros bem elaborados, que apresentam, de fato, renovação linguística e temática e que revelam terem aqueles jovens assimilado a lição dos precursores do Modernismo brasileiro.

No excerto 4, a proposta do revisor mudou radicalmente o sentido. O que nós pretendíamos afirmar, e pensamos ter afirmado, era que os modernistas de Cataguases levaram a literatura a sério. Eles davam muita importância ao seu fazer literário e à busca de levar as ideias renovadoras aos mais diversos pontos do País. Queriam aprender, dialogar. Para eles, a literatura era uma missão, conforme explicou Guilhermino Cesar, em entrevista concedida quando da publicação da edição facsimilar da Revista Verde, patrocinada pela Metal Leve, na década de setenta do século passado. Pela alteração proposta, evidencia-se que o revisor interpretou que "levar a literatura a sério" era a lição dos precursores do Modernismo brasileiro. Essa é uma interpretação possível, mas, se apagarmos “levado

3 DICIONÁRIO ONLINE DE LÍNGUA PORTUGUESA, 2016.

4 Em conversa sobre este artigo, o professor Luiz Francisco Dias, UFMG, ao concordar com o meu comentário, fez a seguinte observação: “Talvez seja aceitável dizer 'portar ideias', mas não é adequado dizer 'portar culturas', uma vez que, no excerto analisado, não se trata de portar conhecimentos culturais, mas de ser investido identitariamente por modos culturais diferentes. Isso não é algo portável, mas constitutivo.” Agradeço ao professor Luiz pela gentileza de ler este artigo e comentá-lo comigo. 
a literatura a sério", como o leitor saberia de que lição se tratava? Além disso, há outras questões em jogo. Por exemplo, considerando que o Modernismo, especialmente na sua primeira fase, não foi um movimento homogêneo, muito ao contrário, foi um movimento marcado pela heterogeneidade de ideias e fazeres literários, não estaria explicitado a que precursores nos referíamos. Neste caso, também, a alteração não foi aceita.

\section{Considerações finais}

Após as reflexões aqui realizadas, é possível voltar às perguntas postas no item anterior. Como lidar com a impossibilidade do real da língua e a incompletude dos sentidos durante a atividade de revisão de textos? É possível ensinar a lidar com essa impossibilidade? No que diz respeito à significação do texto, o que seria uma revisão adequada?

A revisão de textos, como uma intervenção mais radical no real dos sentidos, exige uma elaboração maior do gesto de leitura. Entendemos essa elaboração como um trabalho que se dá no acontecimento de linguagem que ocorre durante a revisão, pelo exercício do olhar cuidadoso, atento, para captar detalhes da forma do texto e, ao mesmo tempo, aspectos da sua significação. Esse trabalho, como penso ter demonstrado, é passível de equívocos, mas isso, por si só, não invalida a revisão. Os equívocos da interpretação podem resultar num efeito de sentido não desejado pelo autor, ou não pertinente ao referencial constituído no acontecimento da escrita; mas podem também resultar em melhorias para o texto.

Não consideramos que seja possível ensinar a revisar, no sentido de que basta apresentar técnicas que possam ser reproduzidas, mas pensamos ser possível proporcionar experiências mais refinadas de leitura, de intervenções no texto e discussão sobre os efeitos de sentido dessas intervenções. É pela experiência e pela reflexão que o aprendizado se dá e que o revisor pode ir construindo suas interpretações. Além disso, para alcançar níveis mais refinados de leitura, é preciso ler muito, pesquisar, questionar o texto e, para o trabalho de revisão, estabelecer um diálogo com o autor, lembrando sempre de que é dele a autoria e, portanto, a palavra final, especialmente no que diz respeito aos sentidos.

No âmbito da significação, uma revisão adequada seria aquela em que o revisor está atento ao movimento dos sentidos e que, ao fazer suas interferências que resultem em mudanças semânticas sutis ou radicais, apresente-as como sugestão a ser discutida com o autor. Como resultado do seu diálogo, aprendem autor e revisor, e ganha o leitor. 


\section{Referências}

CESAR, Guilhermino. Os verdes da Verde. Texto de apresentação da edição fac-similar da revista Verde. São Paulo: Metal Leve, 1978, s/p.

CHAVES, Wilson Camilo. Considerações a respeito do conceito de real em Lacan. Psicologia em Estudo, Maringá, v. 14, n. 1, p. 41-46, jan./mar., 2009. Disponível em: http://www.scielo.br/scielo. php?script=sci_arttex\&pid=S1413-73722009000100006\&Ing=en\&nrm=iso. Acesso em: 14 fev. 2016.

DICIONÁRIO ONLINE DE LÍNGUA PORTUGUESA. Portar. Disponível em: $<$ https://www.dicio. com.br/portar/>. Acesso em: 16 fev. 2016.

HOUAISS. DICIONÁRIO HOUAISS da Língua. Rio de Janeiro: Editora Objetiva, 2007.

FERREIRA, Maria Cristina L. Saussure, Chomsky, Pêcheux: a metáfora geométrica do dentro/fora da língua. Linguagem \& Ensino, v. 2, n. 1, p. 123-137, 1999..

GUIMARÃES, Eduardo J. Texto e enunciação. Organon - Revista do Instituto de Letras da Universidade Federal do Rio Grande do Sul, v. 9, n. 23, p. 63-67, 1995.

GUIMARÃES, Eduardo J. Semântica do Acontecimento: um estudo designativo da designação. 2. ed. Campinas: Pontes, 2005.

JAMAL, Ângela M. A. L.; DALMACHIO, Luciani. A leitura e seus efeitos de sentido: uma perspectiva de análise. In: Anais do SILEL, v. 2, n. 2, Uberlândia: EDUFU, 2011.

LEITE, Nina Virgínia de A. O acontecimento na estrutura. O Real da língua na teorização sobre o discurso: a hipótese sobre o inconsciente. Tese (Doutorado em Linguística) - Programa de PósGraduação em Linguística, Instituto de Estudos da Linguagem da Universidade Estadual de Campinas - UNICAMP, sob a orientação do Prof. Dr. Eduardo Roberto Junqueira Guimarães, Campinas,1993.

MILNER, J. C. Introduction à une Science du language. Paris, Éd. Du Seuil, 1989.

NESTROVSKI, Arthur. Edição como interpretação. In. NESTROVSKI, Arthur. Ironias da modernidade. São Paulo: Ática, 1996. p. 95-99.

ORLANDI, Eni Pulccinelli. A leitura e os leitores. 2. ed. Campinas, SP: Pontes, 2003.

ORLANDI, Eni Pulccinelli. Discurso e leitura. 3. ed. São Paulo: Cortez; Campinas, SP: Editora da Universidade Estadual de Campinas, 1996.

ORLANDI, Eni Pulccinelli. Discurso e texto: formulação e circulação dos sentidos. 3. ed. Campinas, SP: Pontes Editores, 2008.

ORLANDI, Eni Pulccinelli. Interpretação: autoria, leitura e efeitos do trabalho simbólico. 5. ed. Campinas, SP: Pontes Editores, 2007.

SANT’ANA, Rivânia Maria Trotta; GONÇALVES, José Luiz Vila Real. Reflexões acerca das práticas de tradução e revisão de textos e de parâmetros para a formação de tradutores e revisores. Scripta, Revista do Programa de Pós-graduação em Letras e do Centro de Estudos Luso-afro-brasileiros da PUC Minas, v. 14, n. 26, primeiro semestre de 2010.

VANIER, A. Lacan. São Paulo: Estação da Luz, 2005, apud CHAVES, Wilson Camilo. Considerações a respeito do conceito de real em Lacan. Psicologia em Estudo, Maringá, v. 14, n. 1, jan./mar., , p. 41-46, 2009. Disponível em: <http://www.scielo.br/scielo.php?script=sci_arttex\&pid=S141373722009000100006\&Ing=en\&nrm=iso> Acesso em: 14 fev. 2016. 